\title{
Investigations of aluminum fluoride as a new cathode material for lithium-ion batteries
}

\author{
Nathan Owen ${ }^{1} \cdot$ Qi Zhang ${ }^{1}$
}

Received: 7 December 2016 / Accepted: 28 January 2017 / Published online: 20 February 2017

(C) The Author(s) 2017. This article is published with open access at Springerlink.com

\begin{abstract}
Four differently prepared aluminum fluoride samples were tested as cathode materials for rechargeable lithium batteries. The charge-discharge results showed an initial capacity of over $900 \mathrm{mAh} \mathrm{g}^{-1}$ for most of the samples at a voltage of around $2 \mathrm{~V}$, giving specific energy densities of over $7405 \mathrm{~kJ} \mathrm{~kg}^{-1}$, higher than many commercial materials. The cycling results showed an initial high-capacity with rapid capacity fade. The reversible conversion reaction of aluminum fluoride was shown to follow the reduction of $\mathrm{AlF}_{3}$ into $\mathrm{LiF}$ and $\mathrm{Al}$ during discharge and upon charge $\mathrm{Al}$ would be oxidized to form $\mathrm{AlF}_{3}$ and $\mathrm{Li}$ again. It was found that not all the $\mathrm{AlF}_{3}$ would be oxidized due to the large surface/interfacial energy produced by the production of nano $\mathrm{LiF}$ and $\mathrm{Al}$ particles and the large reduction in size from the initial particles to the reduced phase. There was formation of unwanted $\mathrm{Li}_{3} \mathrm{AlF}_{6}$ due to the reaction of $\mathrm{AlF}_{3}, \mathrm{LiF}$, and $\mathrm{LiPF}_{6}$ which also reduced the cycling capacity.
\end{abstract}

Qi Zhang

q.zhang@cranfield.ac.uk

1 School of Aerospace, Transport and Manufacturing, Cranfield University, Cranfield, Bedfordshire MK43 0AL, UK

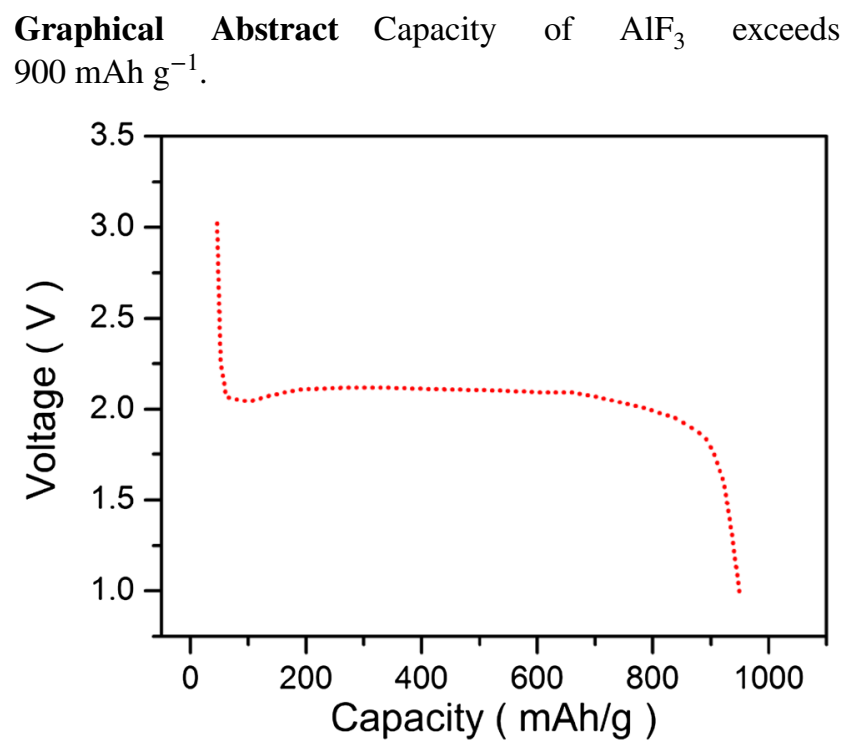

Keywords $\mathrm{AlF}_{3} \cdot$ Cathode $\cdot \mathrm{Li}$-ion batteries . Electrochemical properties

\section{Introduction}

With the increase in complexity of consumer electronics and the need for electric vehicles to compete with current combustion engine vehicles batteries need to improve. The battery chemistry and the search for improved battery materials has intensified over the last few years in order to satisfactorily fill the requirements of the next generation of light-weight and high-capacity electrical storage products. Lithium-ion batteries are currently the most advanced battery technology with the highest specific energy of all 
rechargeable batteries. Current commercialized materials use intercalation compounds which have been developed over the past decade [1]. The problem with intercalation compounds is that there is only either one or less than one electron redox reaction that can take place in the electrode host lattice [2]. In order to increase the specific capacity a new redox mechanism will have to be developed.

The electrochemical conversion reaction utilizes all the available oxidation states of a high valence metal compound and allows a large specific capacity to be realized. A number of metal fluorides, oxides, sulfides, and nitrides have been shown to follow the electrochemical conversion reaction in Eq. (1).

$m n L i^{+}+M_{n} X_{m}+m n e^{-} \leftrightarrow m L i_{n} X+n M^{0}$

The $M$ represents a metal ion and $X$ is an anion belonging to the fluoride, oxide, or sulfide family. The electrochemical reduction of $M_{n} X_{m}$ with lithium produces a $m \mathrm{Li}_{n} X+M$ at discharge. Upon a subsequent charge, the $m \mathrm{Li}_{n} X+M$ reconverts to $M_{n} X_{m}$ taking advantage of the usable valence states of the metal cations for electrical storage [3-6].

The strong ionic character of the M-F bond has been of particular interest due to the metallic cations occupying high oxidation states allowing for high specific capacity and the high redox voltage of the fluorine being offset by the low redox voltage of the metal allowing for a voltage suitable for battery applications.

The main issue with metal fluorides that has hampered their development is the poor conductivity of the material. Many research groups reported in the 1990s a small reversible capacity of $80 \mathrm{mAh} \mathrm{g}^{-1}$ for $\mathrm{FeF}_{3}$. The electrochemical reaction of the conversion mechanism was shown by these groups to be very rate and temperature sensitive [7-9]. This is due to the structural decomposition and reconstruction of the metal fluoride as well as the transport of the lithium ions in the bulk phase. These groups showed that by reducing the size, the lithium pathways are minimized and there is a large area for reversible conversion. By increasing the conductivity and surface area of the $\mathrm{FeF}_{3}$ a few groups have shown a reversible capacity of $\sim 600 \mathrm{mAh} \mathrm{g}^{-1}$ at high rates; however, much of that capacity is at a voltage less than $1.5 \mathrm{~V}$ and not suitable for applications that require a high energy density. Only around $230 \mathrm{mAh} \mathrm{g}^{-1}$ is available in a voltage range that can be used for high energy density applications. This is still more than current commercial lithium battery electrode materials but still not necessary enough to satisfy future high energy products. In order to improve the energy density, a larger capacity at a higher voltage needs to be found.

To this date, no groups have tried testing the metal fluoride $\mathrm{AlF}_{3}$ as an electrode material. It has been used to coat certain materials to improve their cyclability and act as an interfacial stabilizer, as it is proposed to prevent cathode/electrolyte interfacial degradation by the decomposition of the electrolyte at high potentials and stops acidic species from the electrolyte attacking the electrode material [10-17]. It not being used as the electrode material maybe due to it being highly insulating, the redox potential not suitable for use with lithium and aluminum being used as a current collector as it is stable and unreactive in most lithium salt-based electrolytes. By having creating a bond with fluorine, the redox potential is increased to a useable voltage. The theoretical capacity is calculated to be $957 \mathrm{mAh} \mathrm{g}^{-1}$ which corresponds to utilization of three valence states of the reaction of $\mathrm{Al}^{3+}$ to $\mathrm{Al}^{0}$. However, upon repeated cycling this full reduction does not occur, due to either the oxidation process being inefficient, by being hampered by the reduction products, or a detrimental reaction with the electrolyte. It is the inefficiency in the cycling that would have to be improved to make the material suitable for use in applications which require a long cycle life. From the results it is also shown that there is a onestage discharge plateau, for the initial discharge and this is around $2 \mathrm{~V}$, and for subsequent discharges this regresses to $1.6 \mathrm{~V}$ and to around $1.2 \mathrm{~V}$ for the last few cycles. The high voltage discharges around $2 \mathrm{~V}$ occur with a steady flat profile, whereas the subsequent discharges result in a sloping profile.

This study explores the possibility of using aluminum fluoride as an electrode material for high energy density applications and shows initial charge and discharge profiles of the tested materials. This study also aims to investigate the redox reaction of aluminum fluoride.

\section{Experimental procedure}

\subsection{Powder characterization}

Four types of $\mathrm{AlF}_{3}$ powders were tested. The first was a commercially bought powder (from Sigma-Aldrich, further denoted $\mathrm{CP}$ ); the second was the commercially bought powder ball-milled (BM); and the third was the commercial powder ball-milled and coated with a thin carbon coating (further denoted BMc); and the fourth was a carbon aluminum fluoride nanocomposite (NC). The ball-milled samples were prepared by mixing with isopropanol and ceramic mixing balls. The suspension was placed into a desktop ball-mill and run for $240 \mathrm{~h}$. The suspension was dried to leave the ball-milled $\mathrm{AlF}_{3}$. The ball-milled powder was then mixed with polyvinylidene fluoride (PVDF) ( $2 \mathrm{wt} \%$ ) and isoproposal (IPA) for $2 \mathrm{~h}$. The suspension was then dried, and the powder was calcined under argon for $2 \mathrm{~h}$ at $600{ }^{\circ} \mathrm{C}$ to leave a thin layer of carbon coating the $\mathrm{AlF}_{3}$ powder. The nanocomposite samples were prepared by 
high-energy milling $R 3 C \mathrm{AlF}_{3}$ (Sigma-Aldrich) with Super $P$ in a weight $\%$ ratio of $85: 15$, respectively. The powders were placed within a hardened steel milling cell with hardened steel media in a SPEX 8000 high-energy ball-mill and milled for $1 \mathrm{~h}$. All the processes were completed within an inert atmosphere. All the powders were then prepared into either two electrode CR2032 coin cells or a three electrode swagelok cell for electrochemical testing.

PVDF was used as the carbon precursor for coating as it was used in the coating of $\mathrm{CF}_{\mathrm{x}}$ to improve conductivity [18]. There are a number of other coatings that could be used which could be investigated in a future study to test for improvements.

$\mathrm{X}$-ray powder diffraction measurements were performed on a Siemens D5005, and the spectra were taken in the $2 \theta$ range of $5-90^{\circ}$ to confirm the powders phase. Ex situ XRD measurements were taken by opening the coin cells at different states of charge, rinsing in DMC to wash off the electrolyte and left to dry. The dried electrode was then placed on a glass slide and covered with Kapton film using a seal layer of vacuum grease. The resulting electrode was analyzed in the $2 \theta$ range of $5-90^{\circ}$ to confirm the powders phase.

SEM images were taken on a FEI XL30 SFEG analytical SEM (FEI), and a NanoSight LM20 was used to determine the size and particle distribution of the particles. TEM images were taken on a CM20 Scanning TEM (Philips) with the sample being dispersed in a solution of isopropanol and then lifted onto a carbon-coated copper grid for analysis and used to confirm coating of the powders. Ex situ TEM and SAED samples were also prepared by disassembling the coin cells under argon, the electrode rinsed and dispersed in DMC, and a few drops of the dispersion was placed onto a carbon film supported on a copper grid.

\subsection{Electrochemical characterisation}

For electrochemical evaluation, the $\mathrm{AlF}_{3}$ electrode was prepared by mixing $80 \mathrm{wt} \%$ active material, $12 \mathrm{wt} \%$ acetylene black, and $8 \mathrm{wt} \%$ polyvinylidene fluoride (PVDF) and $n$-methyl pyrrolidine with a desktop homogenizer for $10 \mathrm{~min}$ at $7500 \mathrm{rpm}$. The resulting slurry was coated (30 $\mu \mathrm{m}$ thickness) using a doctor blade onto a stainless steel substrate that acted as the current collector. The electrodes with an average mass of $7 \mathrm{mg}$ were assembled in an argon-filled glove box into coin cells using $\mathrm{LiPF}_{6}$ in ethylene carbonate and dimethyl carbonate as the electrolyte and Celgard 2400 microporous membrane as the separator. Cells were cycled at different discharge and charge rates, between 1 and $4.5 \mathrm{~V}$. The cyclic voltammetry and impedance tests were carried out in a three electrode system with lithium metal being the counter and reference electrode using a VersaSTAT 4 potentiostat. The cyclic voltammetry

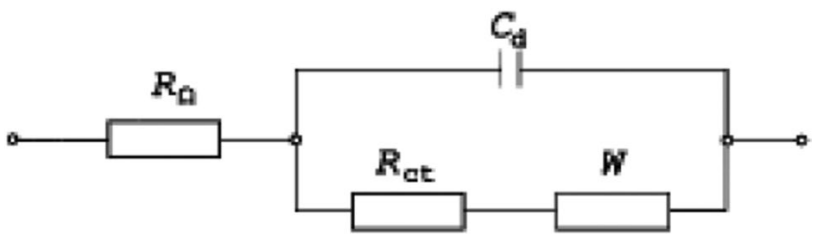

Fig. 1 The schematic of Randles equivalent circuit, where $R_{\Omega}$ is the resistance between electrolyte and electrode, $\underline{R}_{\mathrm{ct}}$ is the charge transfer resistance, $W$ is the Warburg impedance, and $C_{\mathrm{d}}$ is the constant phase element

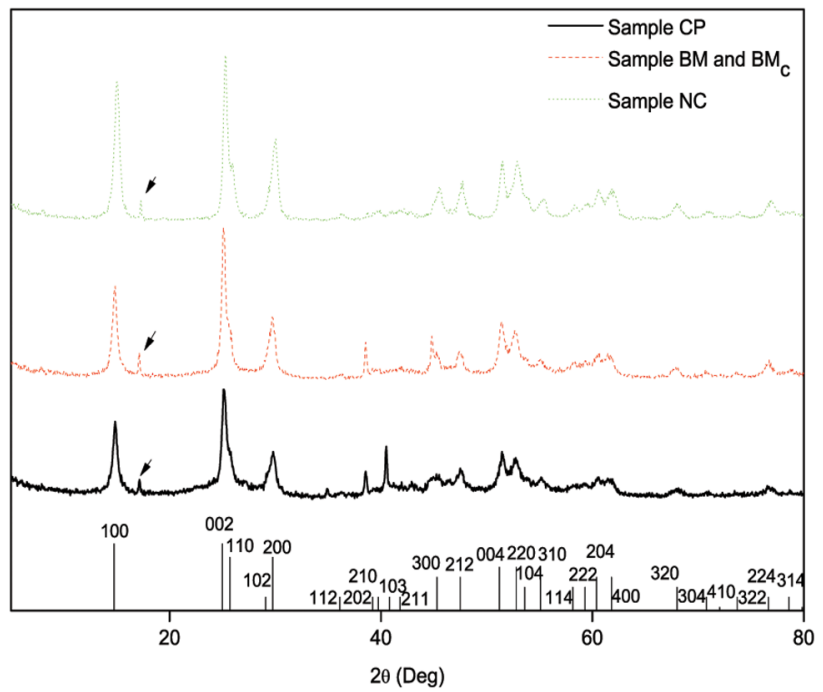

Fig. 2 The XRD pattern of the commercial, ball-milled, and nanocomposite samples. The ball-milled sample is carbon-coated and taken from the same batch as sample BM. The diffraction peaks are indexed against the JCPDS no. 43-0435

used a scanning rate of $0.1 \mathrm{mV} \mathrm{s}^{-1}$ between 1 and $4.5 \mathrm{~V}$. The charge-discharge cycling tests were carried out using a mtixtl battery analyser (Fig. 1).

\section{Results and discussion}

XRD patterns of the commercially bought, ball-milled, and nanocomposite powders are shown in Fig. 2. It shows that three samples are the correct phase with a hexagonal lattice system and space group $P 63 / m m c$. The diffraction peaks of the samples are indexed based on JCPDS no. 43-0435 $\left(\beta-\mathrm{AlF}_{3}\right)$. However, there is a peak present in all the samples which is not indexed on the JCPDS reference indicated with the small arrow. Initially it was thought that the $\mathrm{AlF}_{3}$ samples were reacting to air or moisture but could not be identified as such. The peak was not able to be identified and may have been an issue with the hardware rather than the sample. 

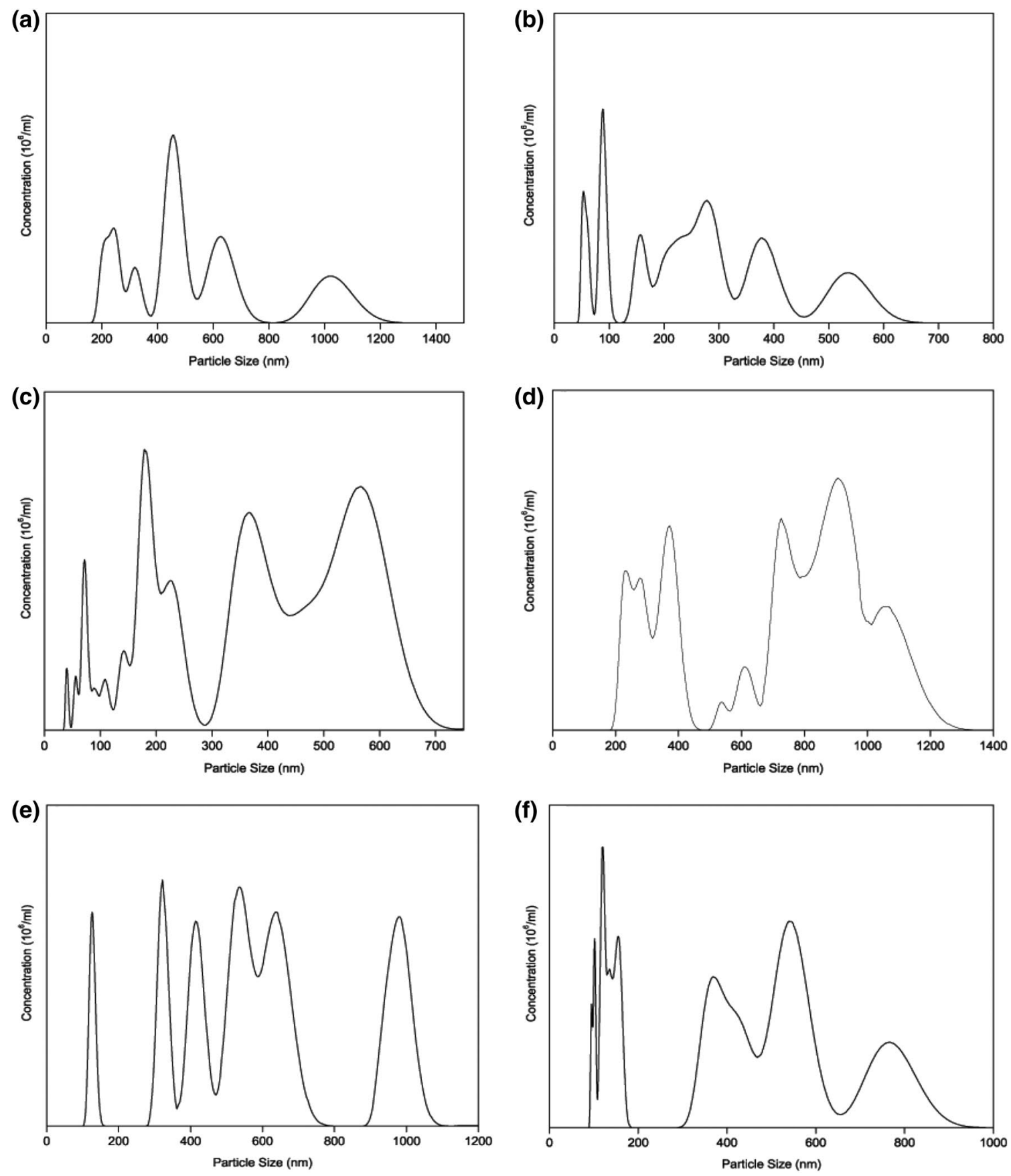

Fig. 3 The average size distribution of samples CP (a), BM (b), and NC (c) taken over three different samples. d-f Show the average size distribution of samples ball-milled for 1 day, 2 days, and 5 days respectively

The size distribution of the commercial powder and the ball-milled powder can be seen in Fig. 3. It can be seen that prior to ball-milling the average particle size, over three different samples, ranges from $200 \mathrm{~nm}$ to over $1000 \mathrm{~nm}$. The highest concentration of particles is around $500 \mathrm{~nm}$ in size (Fig. 3a). After ball-milling and being coated, the average particle size reduces and is in the range of $50-600 \mathrm{~nm}$, with the highest concentration being around $100 \mathrm{~nm}$ (Fig. 3b, c). Images (d) (24 h), (e) (48 h), and (f) $(120 \mathrm{~h})$ show the particle size distribution of four samples ball-milled at different lengths of time. It can be seen that as the ball-milling time is increased, the mean particle size is reduced, and it is the smallest particle size sample that was used in the electrode tests. The sample size did not reduce any further with milling over $240 \mathrm{~h}$. For sample NC, it can be seen that there is a much larger 

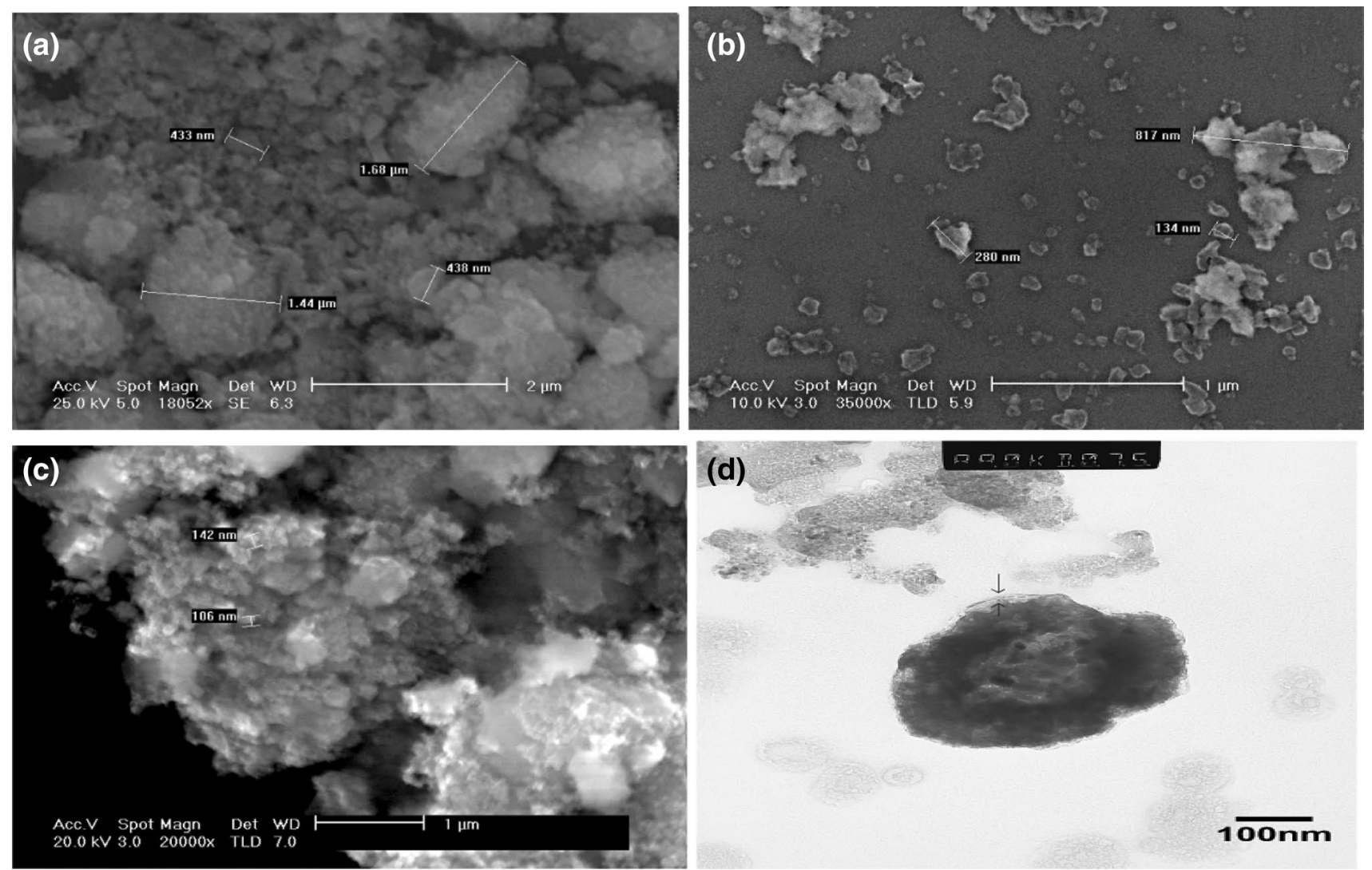

Fig. 4 SEM images of samples CP (a), BM (b), and NC (c). TEM image of the thin carbon coating surrounding the main particle of sample $\mathrm{BMc}$ indicated by the arrows $(\mathbf{d})$

range of particle sizes than in the BM sample, and they are smaller particles. The small size can be attributed to the high-energy ball-mill which can produce smaller particles than the normal ball-mill method. The larger range can be attributed to the formed nanocomposite that is also formed. The carbon contribution would increase the overall size of the particles, depending on how big the nanocomposite agglomeration is. This is confirmed in the SEM images of the samples shown in Fig. 4.

The BM sample can be assumed to be the same size as the BMc sample, as the carbon coating in Fig. 4 shows that the thickness does not add any further size to the diameter of the particle. The carbon coating of BMc can be seen as a thin layer surrounding the main particle shown in the TEM image in Fig. 4.

All the electrochemical tests were carried out at room temperature and in the voltage range of $1-4.5 \mathrm{~V}$. As carbon has no contribution to the specific capacity in this voltage range [19], all the observed capacity can be attributed to the electroactive material $\mathrm{AlF}_{3}$. Figure 5 shows the initial discharge capacities for sample CP at the three tested current rates, 0.01, 0.05, and $0.1 \mathrm{C}$ and samples $\mathrm{BM}, \mathrm{BMc}$, and $\mathrm{NC}$ at their specific discharge rates.
At the slowest discharge rate it can be seen that the initial discharge capacity is over $100 \mathrm{mAh} \mathrm{g}^{-1}$ with an average single-stage voltage of around $1.6 \mathrm{~V}$ (Fig. 5a). It starts around $2 \mathrm{~V}$ and slowly declines until it reaches the lower limit of $1 \mathrm{~V}$. The specific energy density of this material is around $720 \mathrm{~kJ} \mathrm{~kg}^{-1}$ at a discharge rate of $100 \mathrm{~h}$. As the discharge rate is increased it can be seen that the single-stage voltage profile drops, and so does the capacity to around $30 \mathrm{mAh} \mathrm{g}^{-1}$ at a rate of $0.1 \mathrm{C}$. By changing the sample to either BM, BMc, or NC, the initial discharge rate could be increased. It was found that the capacity increased dramatically compared to sample CP. For sample BM, the capacities are over 900 , over 450 , and $125 \mathrm{mAh} \mathrm{g}^{-1}$ for discharge rates $0.1 \mathrm{C}, 0.125 \mathrm{C}$, and $0.17 \mathrm{C}$, respectively (Fig. 5b). For sample BMc, they are over 900 , over 600 , over 250 , and over $40 \mathrm{mAh} \mathrm{g}^{-1}$ for discharge rates $0.1 \mathrm{C}, 0.125 \mathrm{C}, 0.17 \mathrm{C}$, and $0.25 \mathrm{C}$, respectively (Fig. 5c). This was increased even further by using sample NC with $0.1,0.125,0.17,0.25$, and $0.33 \mathrm{C}$ discharge capacities being greater than 900, 700, 400, 100, and $50 \mathrm{mAh} \mathrm{g}^{-1}$ respectively (Fig. 5d).

The poor first discharge capacity for sample $\mathrm{CP}$ can be attributed to the inferior conductivity compared with the other samples. As a current is passed through the material, 

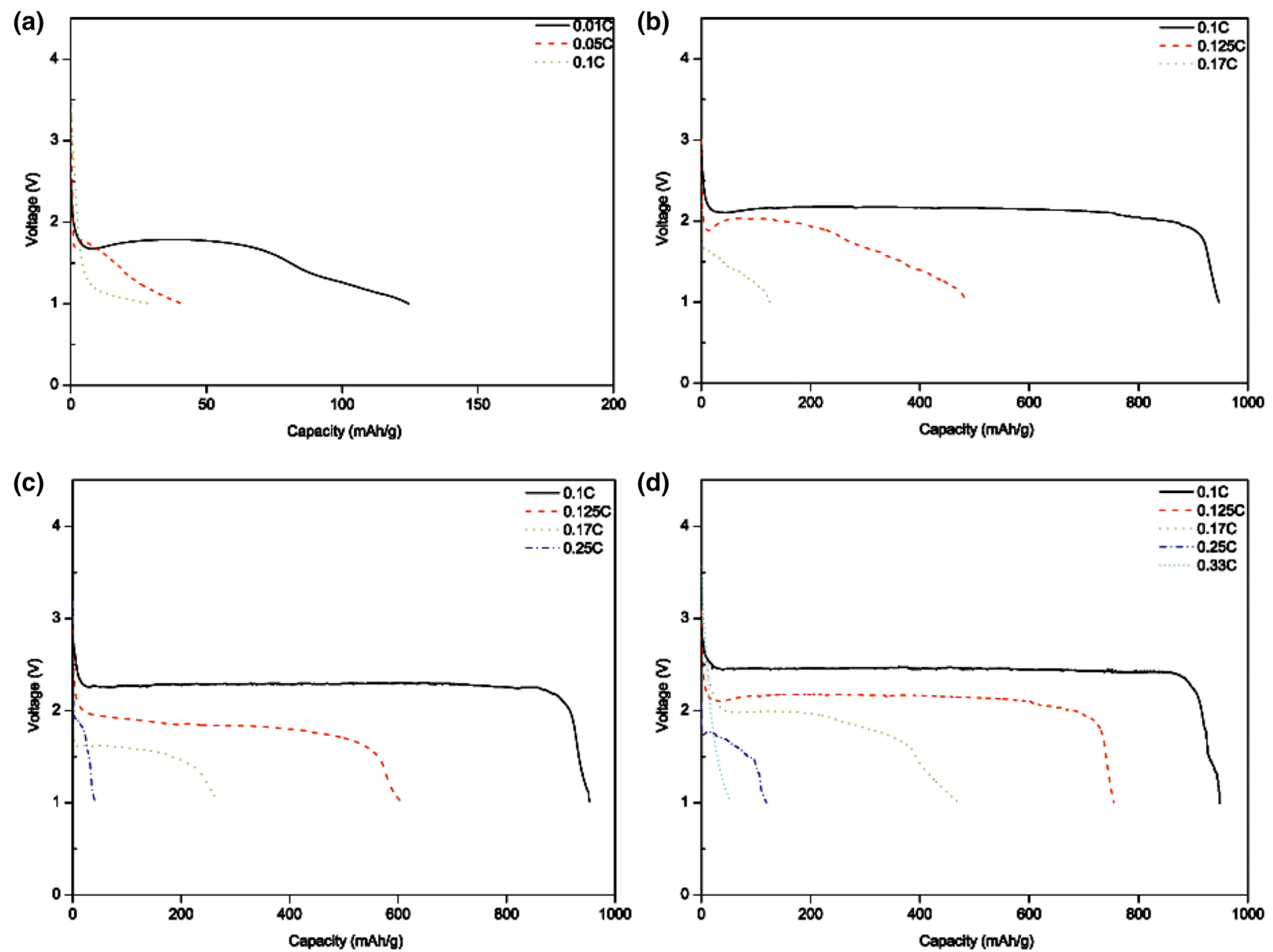

Fig. 5 Discharge capacities of samples $\mathrm{CP}(\mathbf{a}), \mathrm{BM}(\mathbf{b}), \mathrm{BMc}(\mathbf{c})$, and $\mathrm{NC}(\mathbf{d})$, at current densities specified in each image

polarization occurs and the resistance of the material increases. This polarization is a contribution of activation and concentration due to the materials poor conductivity. As the ions pass through the electrolyte and reach the electrode/electrolyte phase boundary, there could be the formation of a passivating SEI layer that makes the electrode become passive. Added to that the inherent poor conductivity of aluminum fluoride, even the low current density passing through the cell could be too fast for the material, a concentration gradient builds up at the electrolyte/electrode interface resulting in a quick drop in potential and reduced capacity as not all the active material has taken part in the reduction. It may be possible to decrease the lower voltage limit to less than $1 \mathrm{~V}$ but there may be a case of unwanted side reactions such as electrolyte decomposition which could attribute to an increase in capacity, and the working voltage would be too low for any real-life applications. This loss in capacity could also be attributed to the average size and shape of the particle resulting in the large diffusion distances of the electrons and ions. Due to the poor conductivity of the large particle powder, the electrons are reaching the electrode surface quicker than they are able to pass through the electrode, causing the electron concentration gradient. It is well known that nm-sized particles give a higher capacity than micron-sized particles $[20,21]$ due to an increase in electroactive surface area and smaller pathways for the electrons and ions to pass through hence increasing electron and ion conductivity, thus reducing concentration polarization and increasing capacity. It can be inferred from the first discharge results of sample BM shown in Fig. 5b that this is the case. The decreased particle size has resulted in the theoretical capacity being achieved for the first discharge cycle at a rate of $0.1 \mathrm{C}$ which is a much higher current density than what sample $\mathrm{CP}$ was put under. However, further increasing the current density results in a rapid reduction of capacity, again due to the inherent properties of the material. In order to try and determine whether the electrolyte being in contact with the bare aluminum fluoride has an effect on increasing activation polarization, sample BM was coated to make 
sample BMc. These results also shown in Fig. 5 infer that the polarization does decrease, as higher specific capacities can be attained at higher rates. The initial discharge plateau of $0.1 \mathrm{C}$ is also shown to have a higher discharge voltage than of the BM sample of $2.3 \mathrm{~V}$ rather than $2.15 \mathrm{~V}$. This initial drop from the open-circuit voltage of around $3.1 \mathrm{~V}$ shows a reduced ohmic polarization due to improved kinetics by reduced particle size. By coating the sample as in $\mathrm{BMc}$ and incorporating a nanocomposite, the kinetics were improved even further and the ohmic drop contribution to polarization was reduced significantly. This also confirms that the total resistance through the cell is decreased as the voltage plateau is increased. This produces an energy density of over $7920 \mathrm{~kJ} \mathrm{~kg}^{-1}$ for sample BMc and over $8100 \mathrm{~kJ} \mathrm{~kg}^{-1}$ for sample NC which is a lot larger than current commercial materials. Even sample BM has an energy density greater than $7380 \mathrm{~kJ} \mathrm{~kg}^{-1}$ which is still larger than many commercial secondary lithium cathode materials. Even sample BM has an energy density greater than $7380 \mathrm{~kJ} \mathrm{~kg}^{-1}$ which is still larger than many commercial secondary lithium cathode materials. However, theoretical calculations using $\mathrm{Al}^{3+}$ redox values put the discharge voltage at $1.39 \mathrm{~V}$ against $\mathrm{Li} / \mathrm{Li}^{+}$and using thermodynamics and the Gibbs free energy the theoretical voltage is $2.89 \mathrm{~V}$, so it is interesting to find different initial voltages. This initial voltage plateau is also increased in sample $\mathrm{NC}$ with a value of $2.4 \mathrm{~V}$ at a discharge rate of $0.1 \mathrm{C}$. The first discharge can be attributed to a thermodynamically changing $\mathrm{AlF}_{3}$ to $\mathrm{LiF}$ which would expect to be seen at around $2.89 \mathrm{~V}$; however, due to the polarizations in the cell this drops and the initial plateau is seen between 2 and $2.5 \mathrm{~V}$. By taking into

Table 1 Energy densities of samples CP, BM, BMc, and NC at particular specified discharge rates

\begin{tabular}{lllll}
\hline Sample & $\begin{array}{l}\text { Discharge } \\
\text { rate }(\mathrm{C})\end{array}$ & $\begin{array}{l}\text { Discharge } \\
\text { capacity } \\
\left(\mathrm{mAh} \mathrm{g}^{-1}\right)\end{array}$ & $\begin{array}{l}\text { Discharge } \\
\text { voltage }(\mathrm{V})\end{array}$ & $\begin{array}{l}\text { Specific } \\
\text { energy density } \\
\left(\mathrm{kJ} \mathrm{kg}^{-1}\right)\end{array}$ \\
\hline $\mathrm{CP}$ & 0.01 & 125 & 1.6 & 720 \\
& 0.05 & 41 & 1.4 & 205 \\
& 0.1 & 29 & 1.2 & 126 \\
$\mathrm{BM}$ & 0.1 & 957 & 2.15 & 7408 \\
& 0.125 & 486 & 1.8 & 1130 \\
& 0.17 & 125 & 1.25 & 324 \\
$\mathrm{BMc}$ & 0.1 & 957 & 2.3 & 7923 \\
& 0.125 & 608 & 1.9 & 4158 \\
& 0.17 & 263 & 1.6 & 1515 \\
& 0.25 & 43 & 1.4 & 216 \\
$\mathrm{NC}$ & 0.1 & 957 & 2.4 & 8269 \\
& 0.125 & 755 & 2.15 & 5842 \\
& 0.17 & 472 & 1.9 & 3229 \\
& 0.25 & 119 & 1.5 & 644 \\
& 0.33 & 54 & 1.3 & 252 \\
\hline
\end{tabular}

account the contribution of fluorine this initial plateau of experimental voltage is closer to the thermodynamically calculated value of 2.89 rather than the voltage of $1.39 \mathrm{~V}$ expected of $\mathrm{Al}^{3+}$ reducing to $\mathrm{Al}^{0}$.

Table 1 shows the energy densities of the tested samples against their initial discharge rate. It shows that upon first discharge, the specific energy density of aluminum fluoride is much larger than the existing commercial secondary battery technologies.

The single-stage discharge plateau recorded at different discharge rates demonstrates a single-step electrochemical reduction process of a three electron reduction of $\mathrm{AlF}_{3}$ to form $\mathrm{Al}$ and $\mathrm{LiF}$. The discharge plateau of the $\mathrm{CP}$ sample has a sloping profile and indicates there is both a solid and liquid phase during discharge. For the other samples, the capacity recorded at the $0.1 \mathrm{C}$ discharge rate indicates a single solid phase as the plateau is flat. Increasing the discharge rate results in a sloping voltage profile indicating that the two phases are present.

It is clear that by reducing the particle size, the polarization through the material has been lowered at the specific discharge currents. By coating the material, the polarization reduces even further so that even higher capacities can be reached at the particular current densities. The low capacity of the CP sample could be attributed to the formation of an SEI layer on the surface of the electrode as it is reaching equilibrium and a steady open-circuit voltage. This electrode surface could contain some electrolyte anions and cations and become passive again increasing the resistance once a current is passed through the cell. However, by adding a layer of carbon as in sample BMc or forming a carbon nanocomposite this carbon layer prevents direct electrode/ electrolyte contact and stops any initial adverse reactions.

Figure 6 shows the voltage profiles of the samples CP, $\mathrm{BM}, \mathrm{BMc}$, and $\mathrm{NC}$ for a discharge rate of $\mathrm{C} / 20$. It can be seen in the less conductive samples $\mathrm{CP}$ and $\mathrm{BM}$ that there is not much of a charging plateau indicating that polarization is so large that Tafel behavior is present and the electrode is irreversible with respect to a large percentage of theoretical capacity. The initial charge capacity is $80 \mathrm{mAh} \mathrm{g}^{-1}$ resulting in a second discharge capacity of $76 \mathrm{mAh} \mathrm{g}^{-1}$ which is less than $8 \%$ of the initial discharge capacity. The discharge capacity for cycle ten is $26 \mathrm{mAh} \mathrm{g}^{-1}$ which is less than $3 \%$ of the initial capacity indicating rapid capacity fade during cycling. By increasing the conductivity of the powder and by introducing a layer between the electrolyte and electrode material, by carbon coating, the initial charge capacity has increased to $125 \mathrm{mAh} \mathrm{g}^{-1}, 13 \%$ of the initial discharge capacity and again undergoes rapid capacity fade to less than $3 \%$ of the initial capacity after ten cycles. Sample NC, however, has a large initial charge of $682 \mathrm{mAh} \mathrm{g}^{-1}$ and a second discharge of $482 \mathrm{mAh} \mathrm{g}^{-1}$, indicating a highly reversible 

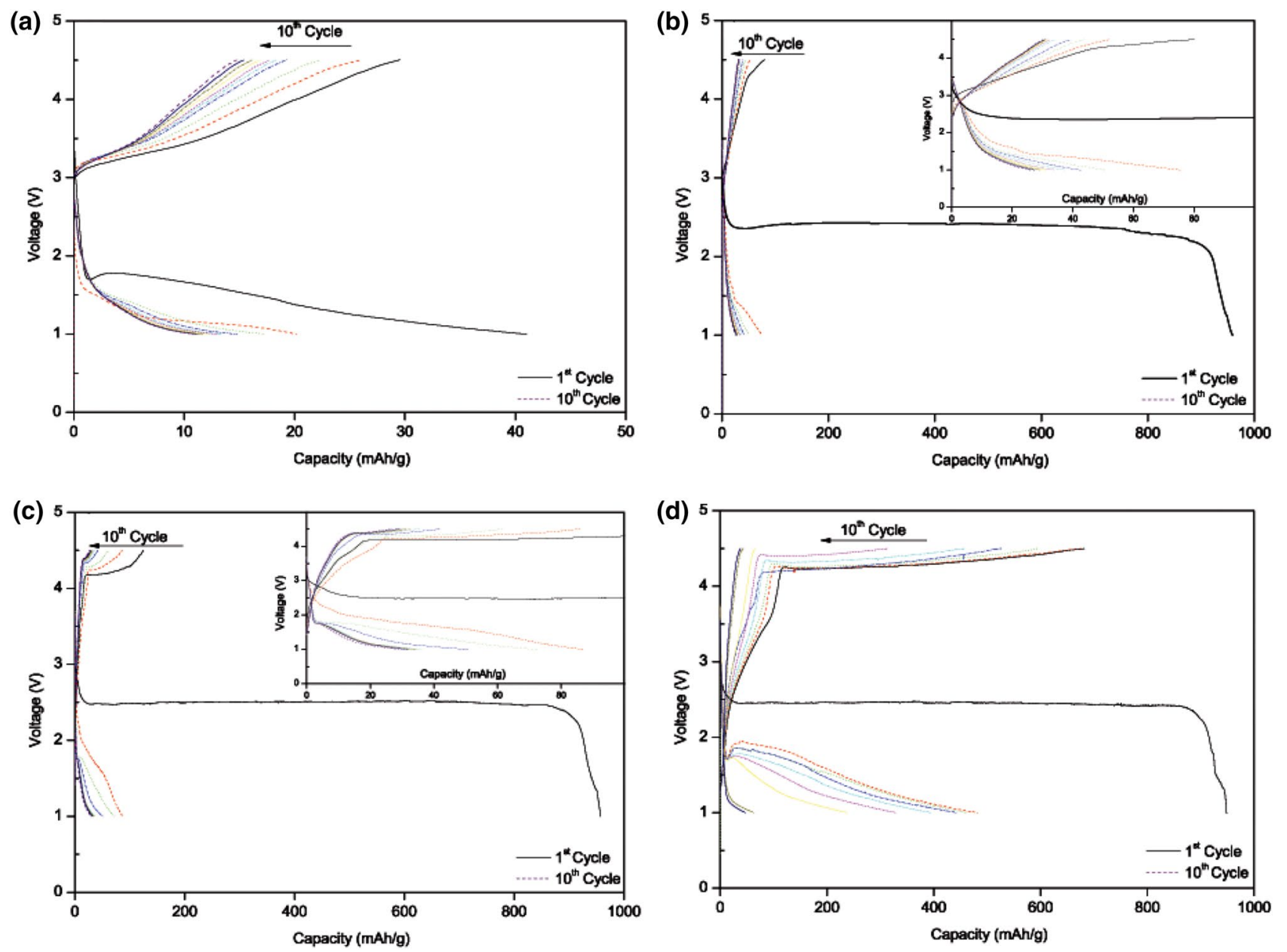

Fig. 6 Cycling profile of samples $\mathrm{CP}(\mathbf{a}), \mathrm{BM}(\mathbf{b}), \mathrm{BMc}(\mathbf{c})$, and $\mathrm{NC}(\mathbf{d})$ at a charge rate of $\mathrm{C} / 100$ and a discharge rate of $\mathrm{C} / 20$. The insets of the graphs show the smaller capacities enhanced

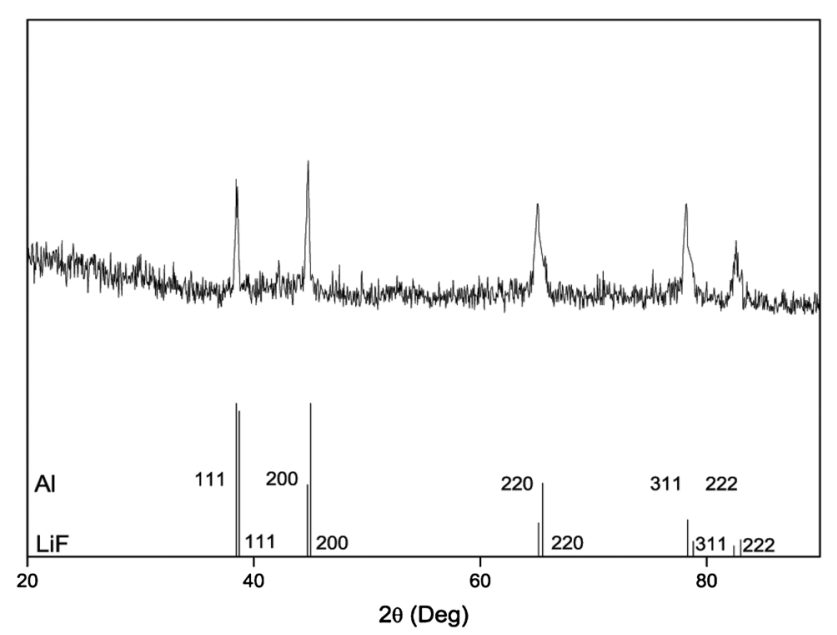

Fig. 7 Ex Situ XRD of sample NC discharged to 1 V. The columns represent the lattice parameters of the identified materials process. This initial reversibility rapidly fades to less than $4 \%$ of initial discharge capacity after ten cycles though. The coating does not seem to have as much effect on the reversibility of the electrode as the nanocomposite. This indicates that there are processes that are involved with the conversion mechanism that reduce the efficiency of the carbon coating or nanocomposite from first discharge to last discharge.

From the initial discharge, it is believed that the $\mathrm{AlF}_{3}$ particles are thought to reduce to form $\mathrm{LiF}$ and $\mathrm{Al}$ according to Eq. (2),

$3 \mathrm{Li}^{+}+3 \mathrm{e}^{-}+\mathrm{AlF}_{3} \longrightarrow 3 \mathrm{Li}+\mathrm{Al}$

This would explain the flat discharge profile seen at around $2.4 \mathrm{~V}$. However, this reduction would result in a large structural rearrangement from $R 3 C$ structure to $F m 3 m$ structure due to the breaking of all the Al-F bonds.

A NC sample was reduced to $1 \mathrm{~V}$ so the reaction products could be determined. Figure 7 shows the ex situ XRD results. Two compounds were identified in the ex situ XRD 


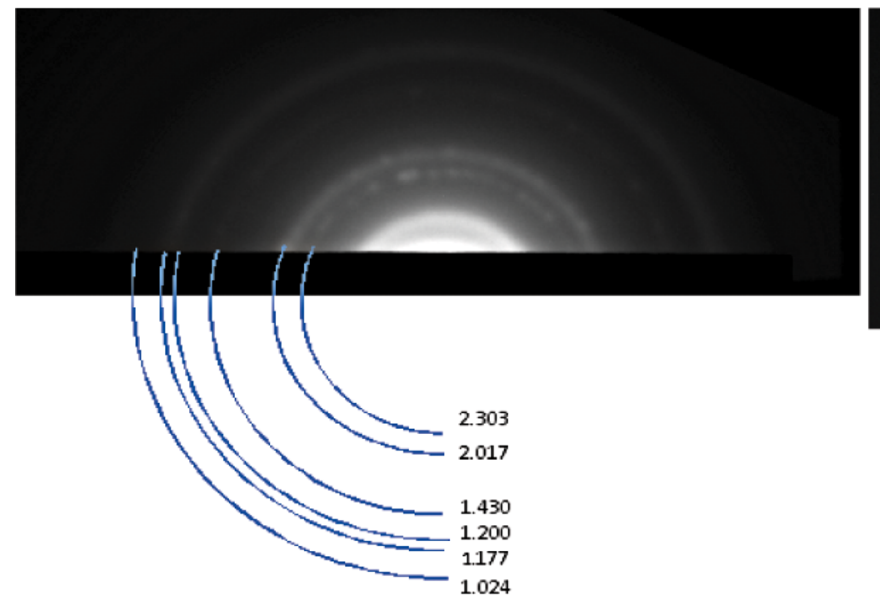

(a)

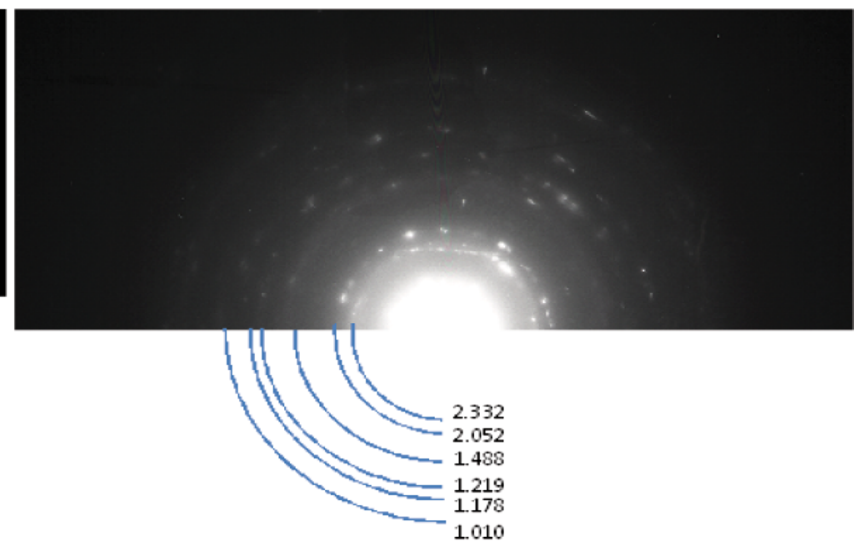

(b)

Fig. 8 Selected area electron diffraction pattern of sample NC discharged to 1 V. Image (a) is of field one, the lithium fluoride product and image (b) is of field two the aluminum product

Table $2 d$-Spacings derived from SAED pattern with a cell fully discharged to $1 \mathrm{~V}$

\begin{tabular}{llll}
\hline IV Field 1 & LiF_Fm3m standard & IV field 2 & Al—Fm3m standard \\
\hline 2.303 & $2.325(111)$ & 2.322 & $2.338(111)$ \\
2.017 & $2.013(200)$ & 2.052 & $2.031(200)$ \\
1.430 & $1.424(220)$ & 1.488 & $1.432(220)$ \\
1.200 & $1.214(311)$ & 1.219 & $1.221(311)$ \\
1.177 & $1.163(222)$ & 1.178 & $1.169(222)$ \\
1.024 & $1.005(400)$ & 1.010 & $1.012(400)$ \\
\hline
\end{tabular}

The standard $\mathrm{LiF}$ and $\mathrm{Al}$ are shown as reference

pattern $\mathrm{LiF}$ and $\mathrm{Al}$ which is consistent with a conversion reaction in Eq. (2).

To further corroborate the ex situ XRD results, selected area electron diffraction patterns were taken on the discharged sample. Figure 8 shows two fields for the sample at room temperature. The $d$-spacings of the diffraction circles can be calculated and are shown in Table 2 against the JCPDS standards.

The broad diffuse diffraction patterns shown in Fig. 8 indicate small crystals, a few nanometers in size. Field 1 had calculated $d$-spacings which agreed enough with the JCPDS standards to confirm that $\mathrm{LiF}$ was one product. Field 2 also had calculated $d$-spacings which agreed enough with the JCPDS standards to confirm that Al was also a product agreeing with the conversion reaction in Eq. (2) and the ex situ XRD patterns shown in Fig. 7. The crystallite sizes $(L)$ were calculated using $L=\frac{K \lambda}{B \cos \theta}$ for peaks (111) and (220), where $B$ is the peak width, $K$ the shape factor, assumed to be one and $\lambda$ the $\mathrm{X}$-ray wavelength, and were $17 \mathrm{~nm}$ and $11 \mathrm{~nm}$ in size, respectively. This is slightly (a)

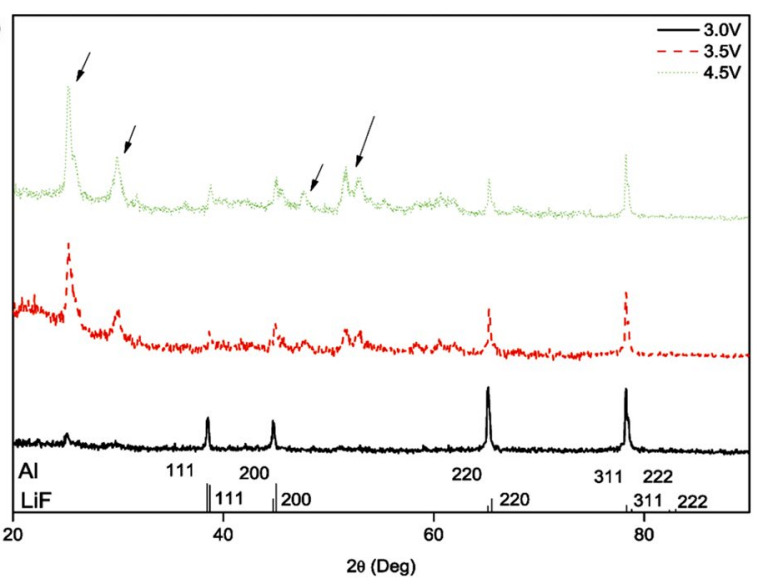

(b)

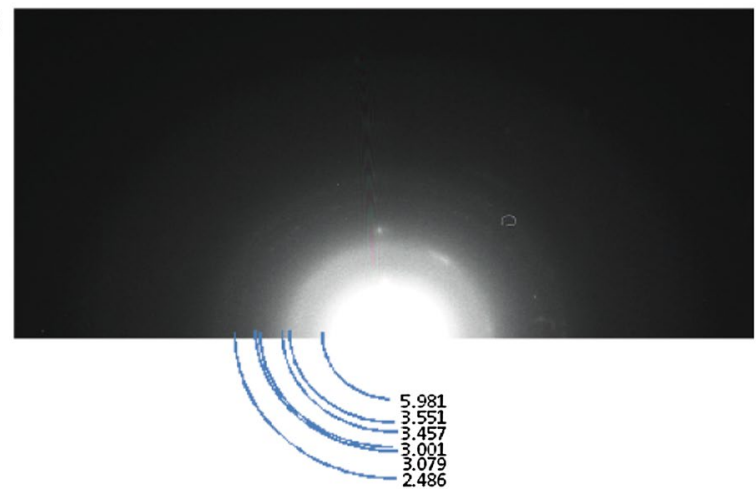

Fig. 9 Ex Situ XRD (a) of sample NC charged to 4.5 V. The columns represent the lattice parameters of the identified materials and the arrows indicate the aluminum fluoride peaks. The voltages the samples were charged to are indicated. Selected area electron diffraction pattern (b) of sample NC charged to $4.5 \mathrm{~V}$ 
larger than the crystallites found when $\mathrm{FeF}_{3}$ was reduced to $\mathrm{LiF}$ and $\mathrm{Fe}$ but that can be attributed to larger cell parameters of $286.65 \mathrm{pm}$ for iron and $404.95 \mathrm{pm}$ for aluminum. The crystallite sizes are smaller than they were before the reduction process.

It seems that the reduction mechanism from $\mathrm{Al}^{3+}$ to $\mathrm{Al}^{0}$ is explained by the one-stage discharge plateau and the subsequent forming of $\mathrm{LiF}$ and $\mathrm{Al}$ nanocomposite. Due to there being no further voltage profile and the plateau being flat, this can be attributed to the reactants and products both forming solid phases. This can be confirmed by the polycrystalline nature of the SAED patterns.

Upon oxidation it is believed that the Li-F bonds can be broken and then the $\mathrm{F}$ reforms with $\mathrm{Al}$ to form $\mathrm{AlF}_{3}$. This oxidation reaction is associated with a $3 \mathrm{e}^{-}$transfer, and subsequent discharge reactions maintained characteristics of the initial compound, a one-stage profile between 2.6 and $1 \mathrm{~V}$.

Figure 9a shows the ex situ XRD patterns for discharged cells which were then recharged to $3,3.5$, and $4.5 \mathrm{~V}$. These potential values were used because it was clear that the charge profile was not at the same voltage as the discharge profile. Upon oxidation it is seen that the Bragg peaks at $38^{\circ}(2 \theta)$ and $43^{\circ}(2 \theta)$ reduce in intensity as do the peaks at $63^{\circ}(2 \theta)$ and $78^{\circ}(2 \theta)$, respectively. This is associated with the oxidation of the $\mathrm{LiF}$ and $\mathrm{Al}$ products formed upon discharge. At $3 \mathrm{~V}$, there is the emergence of peaks around $20^{\circ}$ $(2 \theta)$ which is indicative of $\mathrm{AlF}_{3}$ reforming, and the peaks of $\mathrm{LiF}$ and $\mathrm{Al}$ start to reduce. Upon further charging to $3.5 \mathrm{~V}$, the $\mathrm{LiF}$ and $\mathrm{Al}$ peaks start to become more pronounced which could be due to the reduction in amorphous nature and the crystal structure being more defined as it is oxidizing to reform $\mathrm{AlF}_{3}$. It is at this stage that the $\mathrm{AlF}_{3}$ peaks become more pronounced and more intense suggesting that $\mathrm{AlF}_{3}$ is reforming. At this voltage there still seems to be some $\mathrm{LiF}$ and $\mathrm{Al}$ implying that not all the material has oxidized, or that there has been some dissolution of the $\mathrm{LiF}$ and $\mathrm{Al}$ into the electrolyte. At the final charge voltage of $4.5 \mathrm{~V}$, it is clear that $\mathrm{AlF}_{3}$ has reformed due to the large intensity peaks; however there are still some residual $\mathrm{LiF}$

Table 3 The $d$-spacings derived from the SAED pattern in Fig. 9b with a cell fully charged to $4.5 \mathrm{~V}$

\begin{tabular}{ll}
\hline $\begin{array}{l}\text { Cell charged to } \\
\text { 4.5 V }\end{array}$ & $\begin{array}{l}\mathrm{AlF}_{3}- \\
P 63 m m c \\
\text { standard }\end{array}$ \\
\hline 5.892 & 5.981 \\
5.123 & 3.551 \\
5.032 & 3.457 \\
4.159 & 3.001 \\
3.874 & 3.079 \\
3.561 & 2.486 \\
\hline
\end{tabular}

The standard $\mathrm{AlF}_{3} d$-spacings are shown as reference and Al peaks indicating the oxidization did not occur to all the LiF and Al. This could explain why the theoretical capacity could not be achieved upon the second discharge, not all the $\mathrm{LiF}$ and $\mathrm{Al}$ had oxidized to reform $\mathrm{AlF}_{3}$. However, there does not seem to be any peaks that indicate the adverse reaction of the $\mathrm{LiPF}_{6}$ electrolyte with $\mathrm{AlF}_{3}$ and no peaks that indicate there is an intermediatory phase. These results show that some reversibility is present but due to the poor kinetics and a high overpotential, the reversibility is not efficient. The kinetics of the material can be a major contributing factor to poor oxidation of the reactants due to no anomalous species being present in the electrolyte. Ex situ SAED was also used to confirm this and the SAED pattern of a reconverted region showing $\mathrm{AlF}_{3}$ is shown in Fig. 9b. The subsequently calculated $d$-spacings are shown in Table 3 confirming $\mathrm{AlF}_{3}$. The increased spot development on the SAED pattern shown in Fig. 9b is attributed to the reformation of the $\mathrm{AlF}_{3}$ compound and the diffuse rings indicate small crystal structures. The peaks differ significantly from the discharged sample indicating that some form of oxidation has occurred and with collaboration from the ex situ XRD, it can be put down to the oxidation of $\mathrm{LiF}$ and $\mathrm{Al}$ to form $\mathrm{AlF}_{3}$ as the calculated $d$-spacings match the JCPDS standards.

The fact that the oxidation process does occur shows that the material is reversible; however, there are some inefficiencies that result in poor capacity retention. The initial thought is that upon reduction of $\mathrm{AlF}_{3}$ there is an adverse reaction with the electrolyte resulting in an added phase which does not oxidize back into $\mathrm{AlF}_{3}$. However, during the discharge analysis not enough side products were found that could reduce the capacity by $26 \%$ on the subsequent discharge.

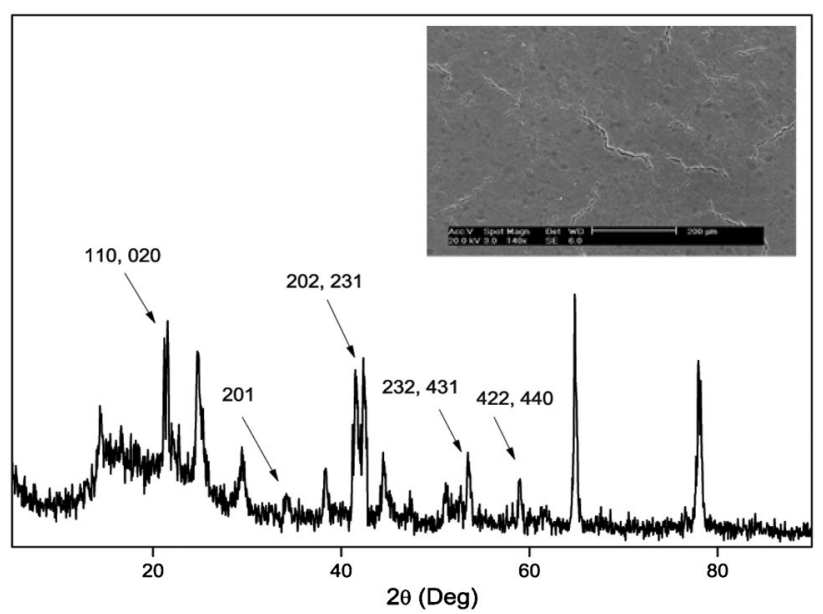

Fig. 10 Ex situ XRD after ten cycles, and the peaks indicated are those of $\mathrm{Li}_{3} \mathrm{AlF}_{6}$ which was found amongst $\mathrm{LiF}, \mathrm{Al}$, and $\mathrm{AlF}_{3}$ peaks. Inset SEM image of cracked electrode after one cycle 
One problem with conversion reactions is the structural change upon cycling. The reconversion from one compound to another degrades the integrity of the electrode resulting in cracking, and this is confirmed by SEM image shown in the inset of Fig. 10 which shows an electrode after one-charge-discharge cycle.

This could result in the dissolution of material into the electrolyte as it breaks off from the electrode. This would also have the effect of there being particles that are not bound to an electrically conductive network of carbon or current collector, making it being a passive material not undergoing any reaction, or the current being too high for the particular particle due to the material's poor kinetics. It was found that upon disassembling the cell that there were loose pieces of electrode in the electrolyte which could contribute to the loss in capacity.

It was found that after a few cycles the capacity dropped considerably and instead of a flat plateau there was a plateau that had a sloping profile. This sloping profile is thought to indicate that the reactants and products are both in liquid and solid solution, whereas the flat profile indicates the reactants and products form two distinct solid phases [22]. As the sloping profile is only apparent after the first discharge the reconversion to $\mathrm{AlF}_{3}$ from $\mathrm{LiF}$ and $\mathrm{Al}$ could be responsible due to a reaction between one of those products and the electrolyte. Over repeated cycling, one of the reduction products could incorporate into the electrolyte either substitutional or interstitially. Figure 10 shows the ex situ XRD of a NC sample cell cycled ten times. The peaks indicated are those of $\mathrm{Li}_{3} \mathrm{AlF}_{6}$ which was found amongst $\mathrm{LiF}, \mathrm{Al}$, and $\mathrm{AlF}_{3}$ peaks. This indicates that upon cycling $\mathrm{LiF}$ reacts with some of the $\mathrm{AlF}_{3}$ to form $\mathrm{Li}_{3} \mathrm{AlF}_{6}$. This product can be regarded as a solid solution of $\mathrm{LiF}$ and $\mathrm{AlF}_{3}$ [22] and can explain the sloping discharge profile. This can also explain the rapid capacity fade as some of the formed $\mathrm{AlF}_{3}$ reacts with $\mathrm{LiF}$ to reduce the actual amount of $\mathrm{AlF}_{3}$ available for the next charge. Both these processes affect the properties of the material by distorting the crystal lattice and disrupt the electrical and physical homogeneity of the solvent material which could also explain the increased charge transfer resistance and resistance between electrode and electrolyte interface through the cell, as discussed above. The cracking of the electrode and dissolution into the electrolyte could also enhance this process and would also account for the loss of capacity witnessed in subsequent cycles. The reconverted crystal sizes calculated from peaks (100) and (004) were $19 \mathrm{~nm}$ and $49 \mathrm{~nm}$, respectively, indicating a size increase of over $200 \%$. The initial particles with a size of around $100 \mathrm{~nm}$ undergo a size reduction of over $90 \mathrm{~nm}$ in the first discharge. They then at least double in size on the subsequent charge. This size fluctuation is enough to understand why the electrode cracks upon repeated cycling.
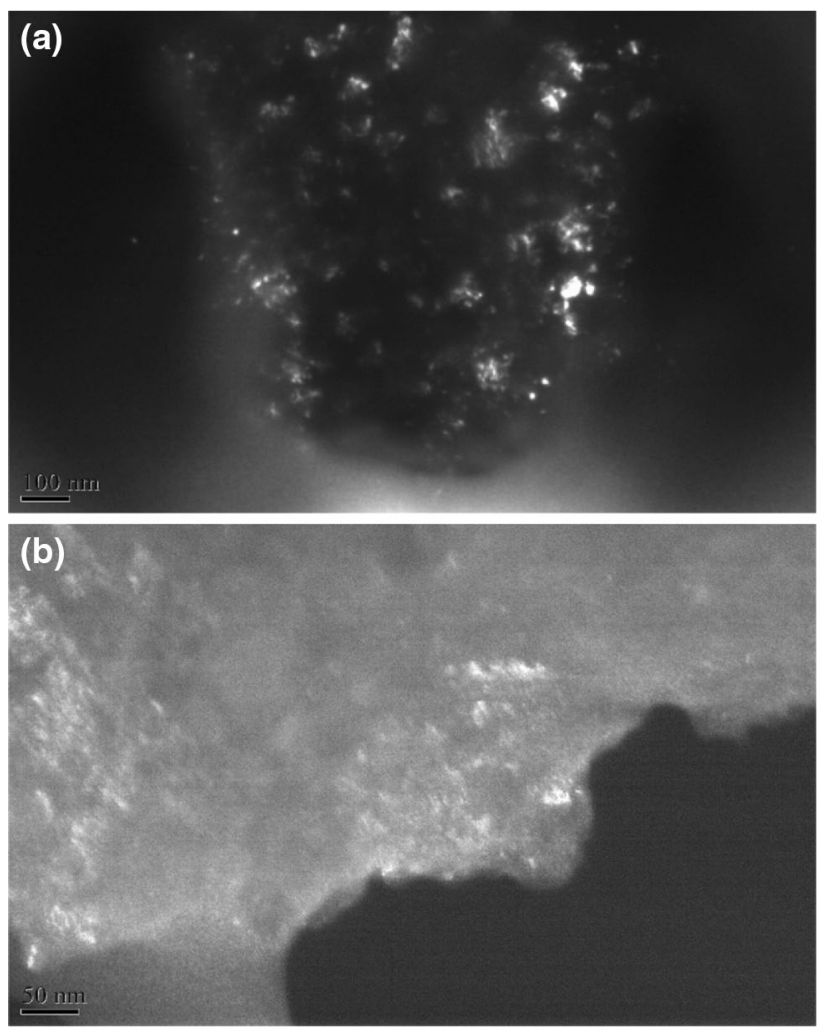

Fig. 11 Dark field image of sample NC before discharge (a) and after discharge (b)

It is also known that once the initial particles are reduced they form a nanocomposite of $\mathrm{LiF}$ and $\mathrm{Al}$ as shown in Fig. 11. The dark field sample shown in Fig. 11a is the sample before it is discharged. The dark area is the carbon and the light areas are the $\mathrm{AlF}_{3}$. It can be seen that there is a large amount of active material combined together to form a nanocomposite with the $\mathrm{AlF}_{3}$ particles being roughly the size determined from the Nanoparticle Tracking Analysis (NTA) in [18]. Upon discharge it can be inferred from Fig. 11b that the products are much smaller and seem to form areas rich in $\mathrm{LiF}$ and $\mathrm{Al}$ as confirmed by EDX. This product of $\mathrm{LiF}$ and Al sits in a nanocomposite of the two where there is a different bonding nature of $\mathrm{LiF}$ (ionic) and $\mathrm{Al}$ (metallic). This large surface contact interface results in a large energy requirement to be put into the system to overcome. This is one explanation to why the charge profile is so much higher than the discharge profile. It may be possible to further increase the charge voltage to see if a higher capacity can be achieved upon a second discharge; however, this would require a high voltage electrolyte as $\mathrm{LiPF}_{6}$ starts to oxidize at higher potentials than $4.5 \mathrm{~V}$. The increase in charge profile could also be due to the cracking of the electrode causing larger impedance due to electrically reduced conductivity through the electrode. 


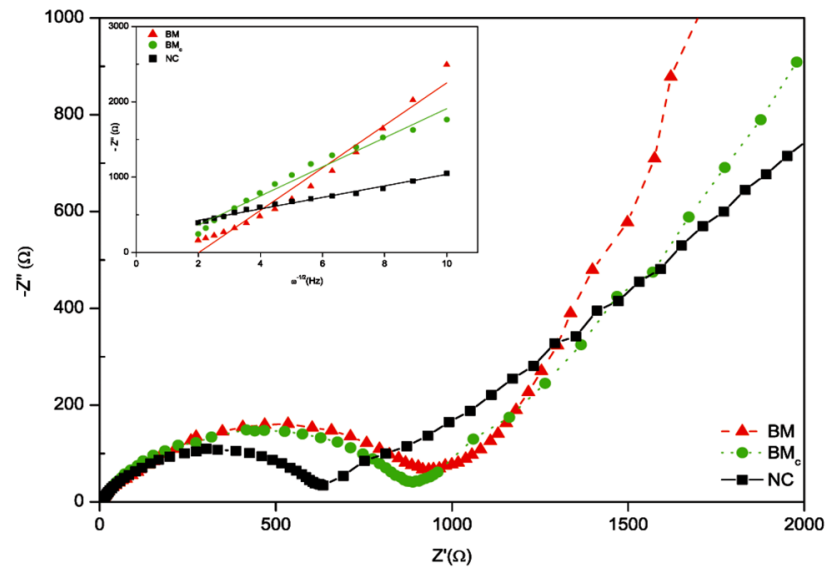

Fig. 12 Nyquist plots of sample BM, BMc, and NC before first discharge. The inset figure is a plot of $-\mathrm{Im} \mathrm{Z}$ against square root of frequency
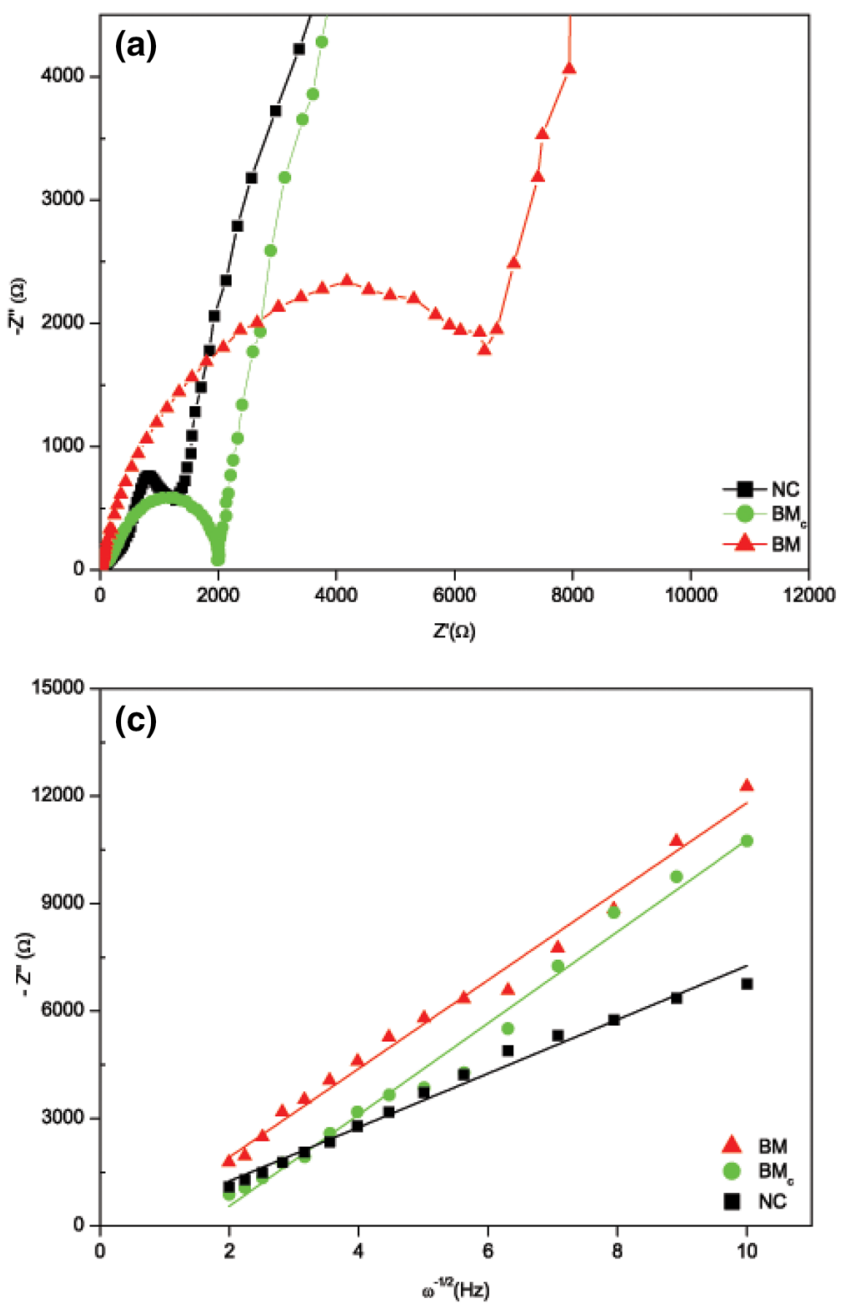

By reducing the cracking it may increase subsequent discharge capacities.

To further test the onset of polarization between a fresh cell, a cell discharged over one cycle, and a cell charged and discharged over ten cycles electrochemical impedance tests were performed. Only samples BM, BMc, and NC were analyzed with EIS due to the initial low capacity of sample CP.

Figure 12 shows the impedance of the samples before any discharge tests were carried out and after the cell was rested to reach equilibrium. The intercept with $\mathrm{Z}^{\prime}(\Omega)$ at the high frequency region of the Nyquist plot corresponds to the ohmic resistance between the electrolyte and the electrode. These are all equal as should be expected as all the cells are in the same state, with no current being passed through them. The radius of the semi-circle in the medium frequency range, which reduces in size for the three
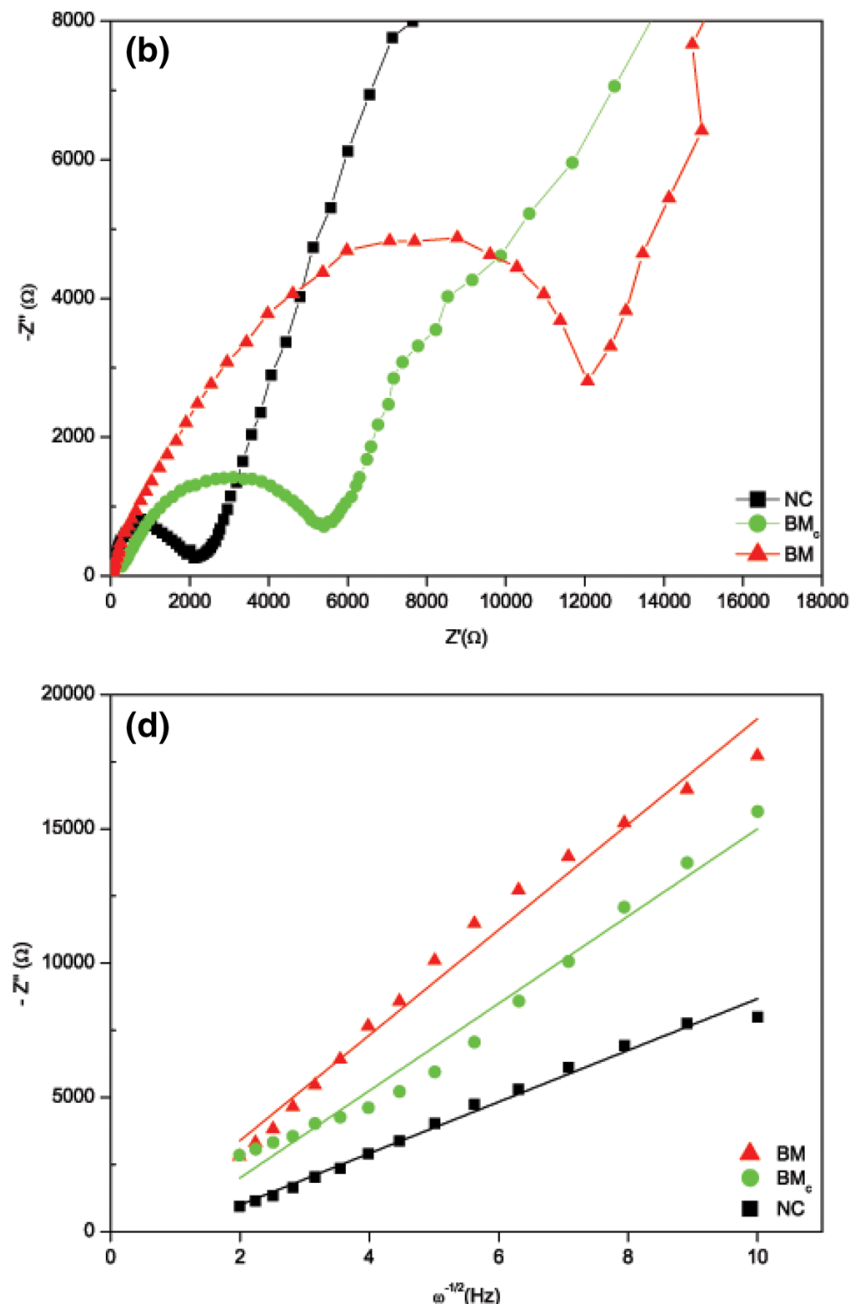

Fig. 13 Nyquist plots of sample BM, BMc, and NC after first discharge (a) and ten (b) cycles. $\mathbf{c}$ and $\mathbf{d}$ are plots of -Im Z against square root of frequency after first discharge and ten cycles, respectively 
Table $4 R_{\mathrm{s}}$ and $R_{\mathrm{ct}}$ values of samples BM, BMc, and NC from Figs. 12 and 13

\begin{tabular}{llllllll}
\hline Sample & $R_{\mathrm{S}}(\Omega)$ & & & \multicolumn{2}{l}{$\underline{R}_{\mathrm{ct}}(\Omega)$} \\
& Fresh cell & $\begin{array}{l}\text { After 1st } \\
\text { discharge }\end{array}$ & Ten cycles & & Fresh cell & $\begin{array}{l}\text { After first } \\
\text { discharge }\end{array}$ & Ten cycles \\
\hline BM & 8.1 & 69.3 & 139 & & 621 & 4021 & 6850 \\
BMc & 7.8 & 32.8 & 78.2 & & 476 & 1034 & 2450 \\
NC & 7.6 & 21.2 & 61.2 & & 331 & 863 & 1105 \\
\hline
\end{tabular}

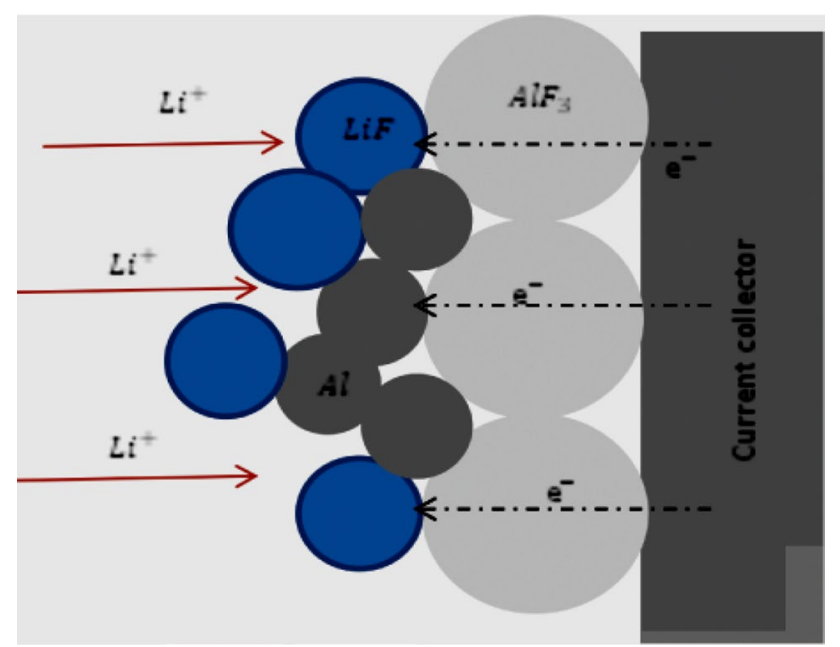

Fig. 14 Schematic diagram of lithium diffusion in electrolyte and electrode

different samples, indicates the charge transfer resistance. It is suspected that the reduced sample size and coating increases the conductivity of the material, and the lithium ions and electrons can transfer with increased speed. The reduction in size of the medium frequency range semi-circle confirms this. An increased charge transfer resistance indicates a larger semi-circle. The inclined line in the low frequency region relates to the Warburg impedance and is plotted against the square root of the frequency in the inset of Fig. 12; this relates to the lithium-ion diffusion through the material. For the three samples it can be seen that sample BM has the largest Warburg impedance and the NC has the smallest which also confirms that reduced particle size and coating has a positive effect on increasing the diffusion properties of aluminum fluoride.

Figure 13 shows the impedance data after the first discharge and after ten charge-discharge cycles and -Im Z against square root of frequency to give an understanding of the diffusion of lithium through the cell. It shows that the impedance of the cells increases quite dramatically after only a few cycles, even after one discharge, indicated by the increase in the $Z^{\prime}(\Omega)$ intercept in the high frequency intercept and the increase in the semi-circle in the medium frequency range. The rise in this impedance is a combination of an increase in charge transfer resistance, polarization
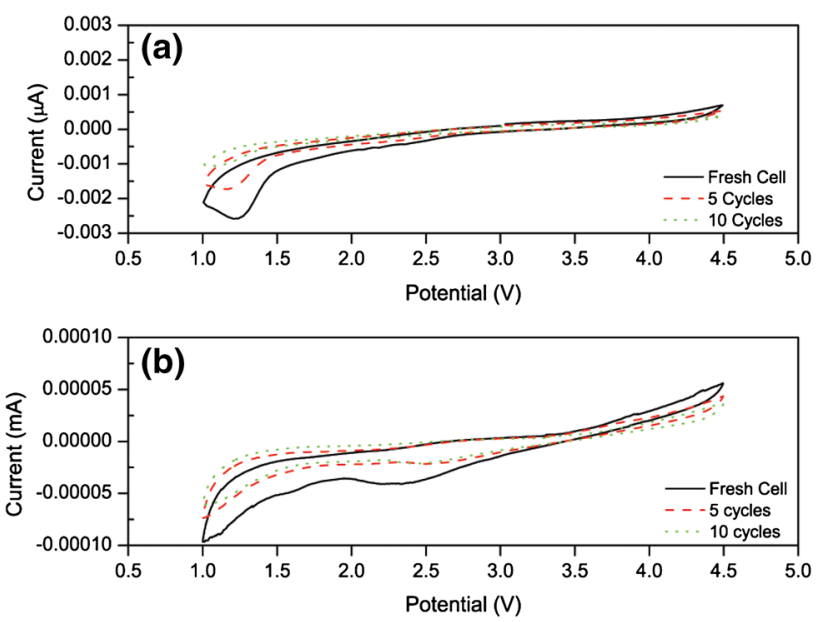

Fig. 15 Cyclic voltammograms of $\mathrm{CP}$ (a) and NC (b). Scan rate $0.1 \mathrm{mV} \mathrm{s}^{-1}$ and after a different number of cycles as indicated in the figures

throughout the interphase between the electrolyte and material and a decrease in the diffusion properties of the lithium ion in the solid. The increase in charge transfer resistance is due to electrode losses due to the potential determining ions being inhabited while trying to pass through the electrode electrolyte phase boundary by the formation of a foreign substance on the electrode surface due to adverse reactions with the electrolyte. This adverse reaction also restricts the current due to concentration changes of the electroactive species at the electrode surfaces, resulting in low current density discharges behaving as if there was a high current passing through the cell, and the discharge profile showing a large drop in voltage with respect to the first charge. This is evident in the discharge profiles shown in Fig. 6.

Table 4 shows the impedance data for $R_{\mathrm{S}}$ and $R_{\mathrm{ct}}$ for the samples BM, BMc, and $\mathrm{NC}$ over the ten cycles. It can be seen that as the cycles increase both the resistances increase due to reactions occurring within the cell.

Figure 14 shows what could be happening. As the aluminum fluoride breaks down the interphase between the electrolyte and lithium fluoride hinders the transport of new lithium ions that would react to the aluminum fluoride nearer to the current collector. This can contribute to the increase in charge transfer resistance and the decreased 
diffusivity through the electrode solid. By coating and reducing the particle size there is a quicker way for the lithium ions and electrons to reach the solid electrode and diffuse through the interphase layer between electrolyte and electrode. However, due to the morphology and relatively large particle sizes, the reaction happens in an agglomerate preventing material blocked by the agglomerate from being reacted with.

Figure 15 shows the cyclic voltammetry curves for $\mathrm{CP}$ and $\mathrm{NC}$ to give a direct comparison of an irreversible and a reversible sample of aluminum fluoride. There is a clear reduction peak for NC between 2.5 and $1 \mathrm{~V}$ which is consistent with the discharge profiles in the previous figures. However, the CV curve for CP does not show a clear reduction peak but a small reduction curve around $1.5 \mathrm{~V}$, which is probably due to the reduced kinetics of the pristine material compared to the nanocomposite material.

There is not a distinct charging plateau for the CP sample but the increase in current for the NC sample after $3.5 \mathrm{~V}$ indicates that there is an oxidation of $\mathrm{LiF}$ and $\mathrm{Al}$ occurring, however small. After the sample is cycled it can be seen that the reduction and oxidation peaks decrease as the polarization through the material increases and no reversible capacity can be observed. Initial investigations look promising that $\mathrm{AlF}_{3}$ can be used as a high-capacity reversible electrode material. If this is not the case, it can still be used as an alternative low-cost material in primary batteries as it has a specific energy density comparable to carbon fluoride primary batteries [18, 23].

\section{Conclusions}

$\mathrm{AlF}_{3}$ with micron and nanometer uncoated, coated, and carbon nanocomposite sized particles were tested as a possible high-capacity electrode material for lithium batteries in CR2032 coin cells at charge-discharge rates of 0.01 , 0.05 , and $0.1 \mathrm{C}$ for ten cycles. Initial discharge capacities were shown to be around $100 \mathrm{mAh} \mathrm{g}^{-1}$ for the micron-sized particles and around $957 \mathrm{mAh} \mathrm{g}^{-1}$ for the other nanometersized particles, at around a plateau ranging from 2.15 to $2.4 \mathrm{~V}$, giving specific energy densities of over $7405 \mathrm{~kJ} \mathrm{~kg}^{-1}$, higher than many commercial materials. The charge-discharge experiments showed that the material was reversible but the specific capacity decreased to less than $5 \%$ of the initial discharge capacity after ten cycles.

The reversible conversion reaction of aluminum fluoride was shown to follow the reduction of $\mathrm{AlF}_{3}$ into $\mathrm{LiF}$ and $\mathrm{Al}$ during discharge, and upon charge $\mathrm{Al}$ would be oxidized to form $\mathrm{AlF}_{3}$ and $\mathrm{Li}$ again. Even though not all $\mathrm{Al}$ was oxidized this was put down to combination of a large voltage required to overcome the large surface/interfacial energy produced by the production of nano $\mathrm{LiF}$ and $\mathrm{Al}$ particles and the large reduction in size from the initial particles to the reduced phase, which resulted in the cracking of the electrode reducing the amount of active material there is to oxidize, which also increased impedance through the cell. The formation of $\mathrm{Li}_{3} \mathrm{AlF}_{6}$ from $\mathrm{AlF}_{3}$ and $\mathrm{LiF}$ during the short cycle life of the cell also indicates there is unwanted side reactions with the $\mathrm{LiPF}_{6}$ electrolyte, with the lack of capacity in subsequent discharges attributed to this phenomenon. It is clear that this material is reversible and it is just a matter of finding the right engineered electrode and compatible cell electrolyte to improve the cyclability. From here there are a few routes to improve this material. One is to synthesize smaller particles so that the initial size reduction is not so great that it causes breaking of the electrode and to increase conductivity through the material. For the first charge, this seemed to be one of the larger contributors to not realizing a rechargeable capacity near theoretical. The decreasing of particle size should also improve the material kinetics so that faster discharge rates and even charge rates could be realized. Another route is to try and find a compatible electrolyte that does not form unwanted products and could perhaps even increase the charge profile up to $5 \mathrm{~V}$, with the idea to improve the cycle life and subsequent cycling capacities. An investigation of the mechanism of the SEI interphase and how it exists in relation to bulk $\mathrm{AlF}_{3}$ interaction is another route that could be taken.

Acknowledgements This work was supported by the Royal Society (Ref: IE111242) through international exchange scheme.

Open Access This article is distributed under the terms of the Creative Commons Attribution 4.0 International License (http:// creativecommons.org/licenses/by/4.0/), which permits unrestricted use, distribution, and reproduction in any medium, provided you give appropriate credit to the original author(s) and the source, provide a link to the Creative Commons license, and indicate if changes were made.

\section{References}

1. Tarascon JM, Armand M (2001) Issues and challenges facing rechargeable lithium batteries. Nature 414:359-367

2. Tarascon JM, Grugeon S, Morcrette M, Laruelle S, Rozier P, Poizot P (2005) New concepts for the search of better electrode materials for rechargeable lithium batteries. C R Chim 8:9-15

3. Li H, Balaya P, Maier J (2004) Li-storage via heterogeneous reaction in selected binary metal fluorides and oxides. J Electrochem Soc 151:A1878-A1885

4. Fan X, Zhu Y, Luo C, Gao T, Suo L, Liou SC, Xu K, Wang C (2016) In situ lithiated $\mathrm{FeF}_{3} / \mathrm{C}$ nanocomposite as high energy conversion-reaction cathode for lithium-ion batteries. J Power Sources 307:435-442

5. Shi YL, Wu N, Shen MF, Cui YL, Jiang L, Qiang YH, Zhuang QC (2014) Electrochemical behavior of iron(III) fluoride trihydrate as a cathode in lithium-ion batteries. ChemElectroChem $1: 645-655$ 
6. Ma R, Wang M, Tao P, Wang Y, Cao C, Shan G, Yang S, Xi L, Chung JCY, Lu Z (2013) Fabrication of $\mathrm{FeF}_{3}$ nanocrystals dispersed into a porous carbon matrix as a high performance cathode material for lithium ion batteries. J Mater Chem 1:15060-15067

7. Arai H, Okada S, Sakurai Y, Yamaki J (1997) Cathode performance and voltage estimation of metal trihalides. J Power Sources 68:716-719

8. Chun J, Jo C, Sahgong S, Kim MG, Lim E, Kim DH, Hwang J, Kang E, Ryu KA, Jung YS, Kim Y, Lee J (2016) Ammonium fluoride mediated synthesis of anhydrous metal fluoridemesoporous carbon nanocomposites for high-performance lithium ion battery cathodes. ACS Appl Mater Interfaces $8: 35180-35190$

9. Bai Y, Zhou X, Zhan C, Ma L, Yuan Y, Wu C, Chen M, Chen G, Ni Q, Wu F, Shahbazian-Yassar R, Wu T, Lu J, Amine K (2017) 3D hierarchical nano-flake/micro-flower iron fluoride with hydration water induced tunnels for secondary lithium battery cathodes. Nano Energy 32:10-18

10. Lin H, Zheng J, Yang Y (2010) The effects of quenching treatment and $\mathrm{AlF}_{3}$ coating on $\mathrm{LiNi}_{0.5} \mathrm{Mn}_{0.5} \mathrm{O}_{2}$ cathode materials for lithium-ion battery. Mater Chem Phys 119:519-523

11. Park BC, Kim HB, Myung ST, Amine K, Belharouak J, Lee SM, Sun YK (2008) Improvement of structural and electrochemical properties of $\mathrm{AlF}_{3}$-coated $\mathrm{Li}\left[\mathrm{Ni}_{1 / 3} \mathrm{Co}_{1 / 3} \mathrm{Mn}_{1 / 3}\right] \mathrm{O}_{2}$ cathode materials on high voltage region. J Power Sources 178:826-831

12. Sun KY, Han JM, Myung ST, Lee SW, Amine K (2006) Significant improvement of high voltage cycling behavior $\mathrm{AlF}_{3}$-coated $\mathrm{LiCoO}_{2}$ cathode. Electrochem Commun 8:821-826

13. Kim JH, Park MH, Song JH, Byun DJ, Kim YJ, Kim JS (2012) Effect of aluminum fluoride coating on the electrochemical and thermal properties of $0.5 \mathrm{Li}_{2} \mathrm{MnO}_{3} \cdot 0.5 \mathrm{LiNi}_{0.5} \mathrm{Co}_{0.2} \mathrm{Mn}_{0.3} \mathrm{O}_{2}$ composite material. J Alloy Compd 517:20-25
14. Tron A, Park YD, Mun J (2016) $\mathrm{AlF}_{3}$-coated $\mathrm{LiMn}_{2} \mathrm{O}_{4}$ as cathode material for aqueous rechargeable lithium battery with improved cycling stability. J Power Sources 325:360-364

15. Zhu Z, Cai F, Yu J (2016) Improvement of electrochemical performance for $\mathrm{AlF}_{3}$-coated $\mathrm{Li}_{1.3} \mathrm{Mn}_{4 / 6} \mathrm{Ni}_{1 / 6} \mathrm{Co}_{1 / 6} \mathrm{O}_{2.40}$ cathode materials for $\mathrm{Li}$-ion batteries. Ionics 22:1353-1359

16. Aboulaich A, Ouzaoult K, Faqir H, Kaddami A, Benzakour I, Akalay I (2016) Improving thermal and electrochemical performances of $\mathrm{LiCoO} 2$ cathode at high cut-off charge potentials by MF3 $(\mathrm{M}=\mathrm{Ce}, \mathrm{Al})$ coating. Mater Res Bull 73:362-368

17. Wu Q, Yin Y, Sun S, Zhang X, Wan N, Bai Y (2015) Novel AlF3 surface modified spinel LiMn1.5Ni0.5O4 for lithium-ion batteries: performance characterization and mechanism exploration. Electrochim Acta 158:73-80

18. Zhang Q, d'Astorg S, Xiao P, Zhang X, Lu L (2010) Carboncoated fluorinated graphite for high energy and high power densities primary lithium batteries. J Power Sources 195:2914-2917

19. Mochida I, Ku C, Koral Y (2001) Anodic performance and insertion mechanism of hard carbons prepared from synthetic isotropic pitches. Carbon 39:399-410

20. Guo Y, Hu JS, Wan LJ (2008) Nanostructured materials for electrochemical energy conversion and storage devices. Adv Mater 20:2878-2887

21. Arico AS, Bruce P, Scrosati B, Tarascon JM, Van Schalkwijk W (2005) Nanostructured materials for advanced energy conversion and storage devices. Nat Mater 4:366-377

22. Vincent C, Scrosati B (1997) Modern batteries: an introduction to electrochemical power sources. Wiley, New York

23. Amatucci GG, Pereira N (2007) Fluoride based electrode materials for advanced energy storage devices. J Fluorine Chem 128:243-262 